\title{
Regional differences in incidence and mortality trends in cancers of the larynx, thyroid, oral cavity and pharynx in England and Scotland: 1975-2002
}

\author{
Oladejo Olaleye ${ }^{1}$, Somiah Siddiq ${ }^{2}$, Udeme Ekrikpo ${ }^{3}$, Rehan Kazi $^{4}$ \\ ${ }^{1}$ University Hospitals Coventry \& Warwickshire NHS Trust, Coventry, UK \\ ${ }^{2}$ University Hospitals Birmingham NHS Trust, Birmingham, UK \\ ${ }^{3}$ University of Uyo Teaching Hospital, Uyo, Nigeria \\ ${ }^{4}$ The Royal Marsden NHS Hospital, London, UK \\ Email:dejolaleye@yahoo.com, somiah@doctors.org.uk, udekrikpo@yahoo.com,drrehankazi@gmail.com
}

Received 26 September 2012; revised 25 October 2012; accepted 3 November 2012

Copyright (C) 2013 Oladejo Olaleye et al. This is an open access article distributed under the Creative Commons Attribution License, which permits unrestricted use, distribution, and reproduction in any medium, provided the original work is properly cited.

\begin{abstract}
Context: There have been significant changes in the epidemiology of head and neck cancers (HNC) in the last three decades worldwide. Documenting these trends helps to facilitate cancer prevention measures and aids resource allocation. Objective: To analyse incidence and mortality trends in Head and Neck Cancers (HNC) in the UK and compare regional differences between England and Scotland. Design: Retrospective quantitative analysis of time trends of HNC cases in the UK recorded in the International Agency for Research into Cancer (IARC) CI5 database and WHO mortality database. Setting: Cancer databases with extraction of UK HNC incidence and mortality time trends. Patients: All patients with cancers of the larynx, thyroid, oral cavity and pharynx in the UK (1975-2002) recorded in the IARC and WHO databases. Main Outcome Measures: HNC incidence and mortality trends in the UK. Results: There has been an increase in incidence of oral and pharyngeal cancer in the UK especially among males with higher rates in Scotland. However mortality has increased in Scotland and reduced in England. Thyroid cancer incidence has increased in the UK especially among females with higher rates in Scotland. Mortality has reduced in both regions. Laryngeal cancer among males has increased in incidence particularly in Scotland with a decline in incidence in England. Mortality has reduced significantly in England among males but increased in Scotland. Conclusions: In the UK, Scotland has higher incidence rates of HNC compared with England. Mortality has reduced in England from all the HNC sub-sites but has
\end{abstract}

increased in Scotland for laryngeal, oral \& pharynxgeal cancers. Although socioeconomic deprivation and its relation to higher alcohol and tobacco consumption have been highlighted as drivers, further studies are required.

Keywords: Head; Neck Cancers; Epidemiology; Thyroid; Laryngeal; Oral; Pharyngeal Cancers; UK; Incidence; Mortality

\section{INTRODUCTION}

There have been significant changes in the epidemiology of head and neck cancers (HNC) in the last three decades worldwide. This study analyses incidence and mortality trends in HNC in the UK and compares regional differences between England and Scotland. This will facilitate cancer prevention and resource allocation.

The head and neck cancer types included in this study are laryngeal, thyroid, oral and pharyngeal cancers. These cancers are the commonest HNC and demonstrated significant epidemiological trends in the period under review. Studies have reported increasing incidence of thyroid cancer in many countries in America and across Europe. In particular, differentiated thyroid cancers (papillary and follicular variants) have been shown to be on the increase. It is thought that may be due to increased diagnostic scrutiny with ultrasound scans picking up "incidentalomas". In some countries with a history of exposure to significant radiation such as the Chernobyl nuclear disaster, the incidence of thyroid cancers has justifiably increased.

Oral and pharyngeal cancers are also on the increase primarily due to exposure to the known risk factors of 
alcohol consumption and cigarette smoking. There are regional differences seen across countries including the UK directly related to the degree of consumption of both alcohol and cigarettes. Higher rates of these cancers are found in countries with higher rates of exposure to these lifestyle risk factors. In recent decades, human papilloma virus has emerged as another significant driver for certain oropharyngeal cancers with an apparent epidemiologic and molecular difference compared to HPV negative tumours. There is still a lot not yet understood about HPV positive tumours but they appear to present in the younger age group and seem to respond better to treatment. Documenting these recent epidemiologic trends is crucial.

Laryngeal cancers on the other hand, are strongly associated with cigarette smoking and there has been a steady decline in laryngeal cancer incidence in England over the last 30 years that correlates with the falling rates of smoking. The experience in Scotland is different as there are higher rates of risk factor exposures with attendant mortality.

Studies have shown a strong correlation between socioeconomic factors and the development of cancers. There are regional differences between England and Scotland with some of the most deprived communities located in Scotland. This may be a contributory factor to the HNC rates although it is yet unproven and this study does not have that data to present.

We aim to present the changing time trends for each HNC sub-site with a view to directing resources and encouraging exploratory studies to explain the observed trends.

\section{METHODS}

\subsection{Patients and Study Design}

This is a retrospective quantitative analysis of time trends of HNC cases in England and Scotland recorded in the International Agency for Research into Cancer (IARC) CI5 database. Mortality trends were analysed from the WHO database.

Ethical approval was not required as the data is publicly available and provided by IARC. The data from IARC and the WHO was completely anonymised and as such there was no direct contact with any patients on the database. The IARC grants use of its data in the form provided and cited.

\subsection{Statistical Analysis}

Age-standardised incidence and mortality rates were recorded for England and Scotland over the study period by IARC. Using STATA, statistically significant trends were sought for each HNC sub-site in each country.
Trend test for each graph was performed. A p-value less than 0.05 was deemed statistically significant.

\section{RESULTS}

\subsection{Oral and Pharyngeal Cancer}

Age-standardised incidence rates (ASIR) in Scotland for males rose from 8.35 per 100,000 in 1975 to 11.0 per 100,000 in 2002, p $<0.001$ (Figure 1). In females, the rates also increased from 3.37 per 100,000 in 1975 to 5.04 per 100,000 in 2002, $p<0.001$. Mortality increased significantly among males $(\mathrm{p}<0.001)$ but not in females ( $\mathrm{p}=0.19)$.

In England, ASIR in males increased from 5.57 per 100,000 in 1985 to a peak 8.21 per 100,000 in 2001 , p < 0.001 (Figure 1). In females, there was also an increase in ASIR from 2.91 per 100,000 in 1985 to a peak 3.82 per 100,000 in $2001, p=0.001$. Mortality reduced significantly among females $(\mathrm{p}<0.001)$ but not in males ( $\mathrm{p}$ $=0.06$ ).

\subsection{Thyroid Cancer}

In Scotland, there was an increase in ASIR in females from 1.66 per 100,000 in 1975 to a peak 3.37 per 100,000 in 2001, $\mathrm{p}<0.001$ (Figure 2). In males, ASIR changed from 0.86 per 100,000 in 1976 to 0.97 per 100,000 in $2002, p=0.004$. Mortality reduced significantly among females $(p=0.001)$ with no change among males $(\mathrm{p}=0.25)$.

In England, there was a significant increase in ASIR in females from 1.62 per 100,000 in 1985 to a peak 2.96 per 100,000 in 2002, $p<0.001$. In males, there was a significant change in ASIR with 0.69 per 100,000 in 1985 to 0.89 per 100,000 in $2002(\mathrm{p}=0.001)$. Mortality reduced among both males and females, $\mathrm{p}<0.001$ and $\mathrm{p}=$ 0.01 respectively.

\subsection{Laryngeal Cancer:}

In Scotland, there has been a significant increase in ASIR in males from 4.08 per 100,000 in 1975 to 6.67 per $100,000$ in 2001 ( $\mathrm{p}<0.001)$. In females, ASIR was 1.16 per 100,000 in 1975 and 1.28 in 2002. Mortality increased from 1.96 per 100,000 in 1975 to 2.48 per 100,000 among males, $\mathrm{p}=0.001$ (Figure 2) with no change among females $(\mathrm{p}=0.16)$.

In England, there has been a decline in ASIR for laryngeal cancer among males from 4.37 per 100,000 in 1985 to 3.85 per 100,000 in 2002, p = 0.04 (Figure 1). In females, there has been no change in ASIR with 0.79 per 100,000 in 1985 to 0.81 per 100,000 in 2002. Mortality reduced significantly among males from 1.80 per 100,000 in 1975 to 1.31 per 100,000 in 2002, $\mathrm{p}<0.001$ (Figure 3) and among females from 0.34 to 


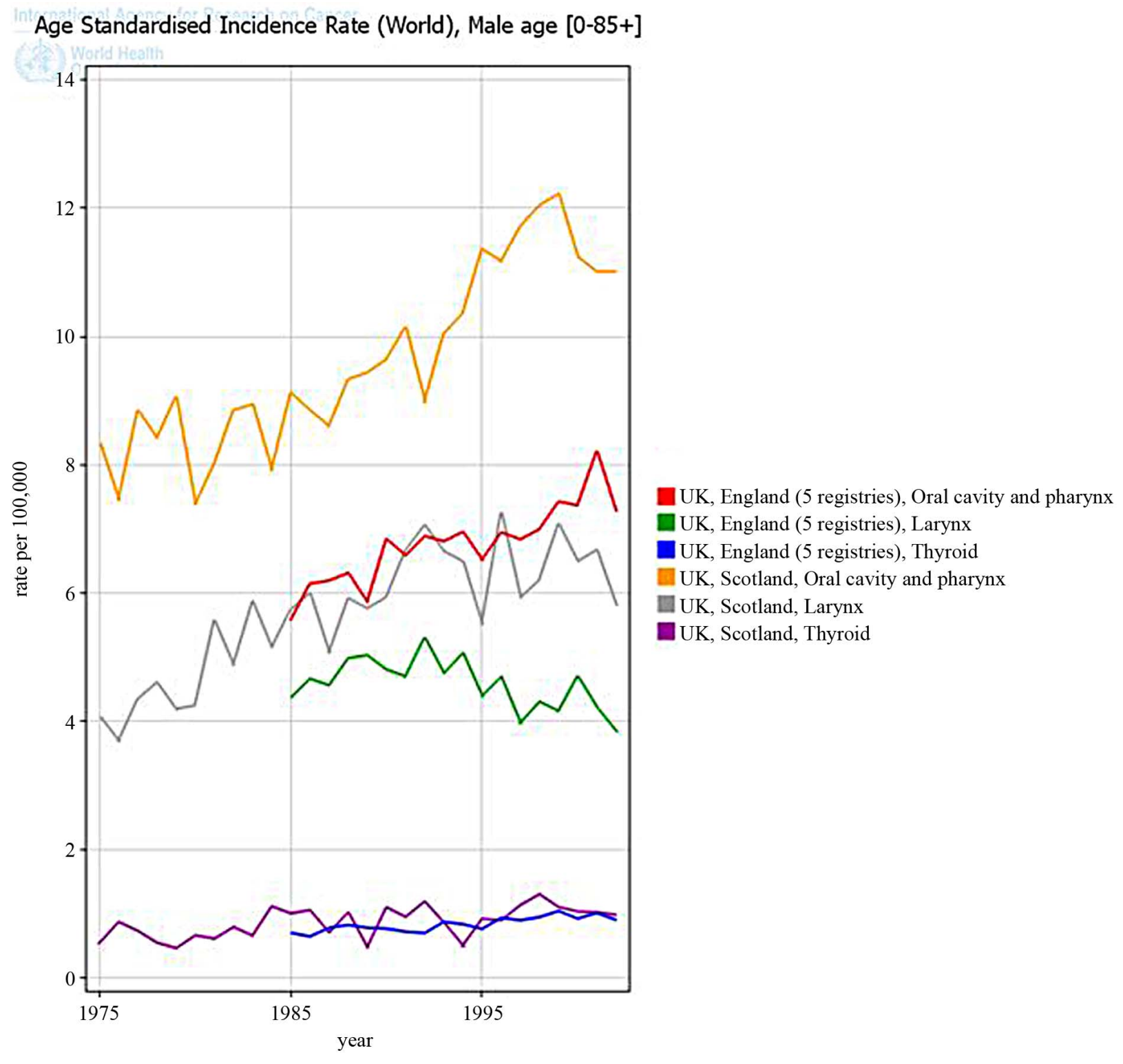

International Agency for Research on Cancer (IARC) - 2.12.2011

Figure 1. Age-standardised incidence rates in males in UK for cancers of the larynx, thyroid, oral cavity and pharynx.

to 0.24 per $100,000 \mathrm{p}<0.001$ (Figure 4).

\section{DISCUSSION}

\subsection{Thyroid Cancer}

Thyroid cancer is the most common endocrine malignancy [1] and its incidence has increased over the last 30 years. Increasing incidence of differentiated thyroid cancer has been reported within USA, Europe and Canada [2].

Our study confirms worldwide trends and support recent published UK studies. Increased incidence in welldifferentiated (papillary and follicular) histological types, in females and young adults within the South East of
England between 1987-2006 have been previously highlighted [3,4]. Overall thyroid cancer increase between 1960-2002 in Scotland was noted to be primarily due to an increase in papillary cancer of all the histological subtypes with no significant change noted in the incidence of medullary and anaplastic thyroid cancer [3].

Improved detection and screening of smaller tumours ( $1-2 \mathrm{~cm}$ ), (since the wider use of ultrasound imaging in the early 1980s), and changes in clinical practice/histological criteria has been suggested to explain such rising trends.

SEER (Surveillance, Epidemiology and End Results) database analysis between 1998 and 2002 suggested that micropapillary thyroid cancer $(<1 \mathrm{~cm})$ accounted for 


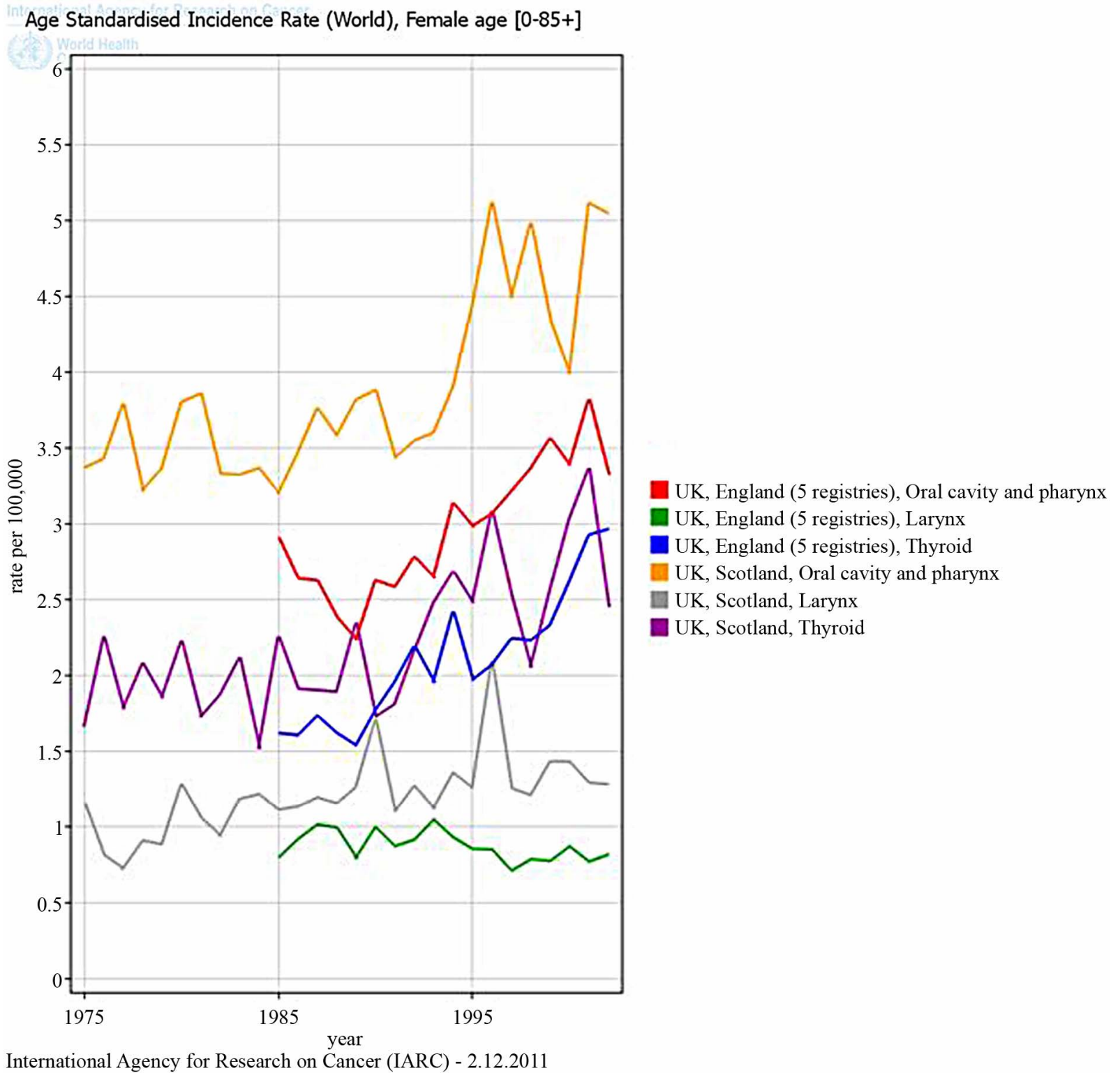

Figure 2. Age-standardised incidence rates in females in UK for cancers of the larynx, thyroid, oral cavity and pharynx.

$49 \%$ of the overall increased incidence in thyroid cancer [5]. Furthermore, increased pathological reporting of micropapillary thyroid cancer in benign thyroid disease, on a background of evolving classification of histological criteria in thyroid malignancy over the last 30 years, has been suggested to explain current trends [5].

However, the theory that increased incidence rates reflects increased detection of subclinical disease, does not fully account for the greater rise in incidence in the developing world (where imaging remains limited) and the rise in detection of larger tumours $(>2 \mathrm{~cm})$ and more advanced thyroid cancer $[1,6,7]$. Further population-based studies based on the SEER database between 1973 and 2006, have shown incidence has more than doubled in well-differentiated thyroid cancers of palpable size $(>2$ $\mathrm{cm})$ and larger $(>4 \mathrm{~cm}$ and $>6 \mathrm{~cm}$ ) tumours [6].

Therefore, early detection or over-diagnosis does not fully account for the current rising trends and radiation exposure, hormonal, dietary/obesity, genetic or environmental risk factors have been suggested as possible areas of further investigation $[1,6]$.

Radiation exposure, particularly in childhood, following nuclear fallout post nuclear weapon testing and Chernobyl has been identified as a cause in the development of thyroid cancer.

Limited studies exist to account for the disparity in thyroid cancer incidence rates in Scotland compared to England. An epidemiological study [8] within the UK focusing on trends during 1962 to 84 noted a peak in thyroid cancer risk in women born in the early 1950's, 


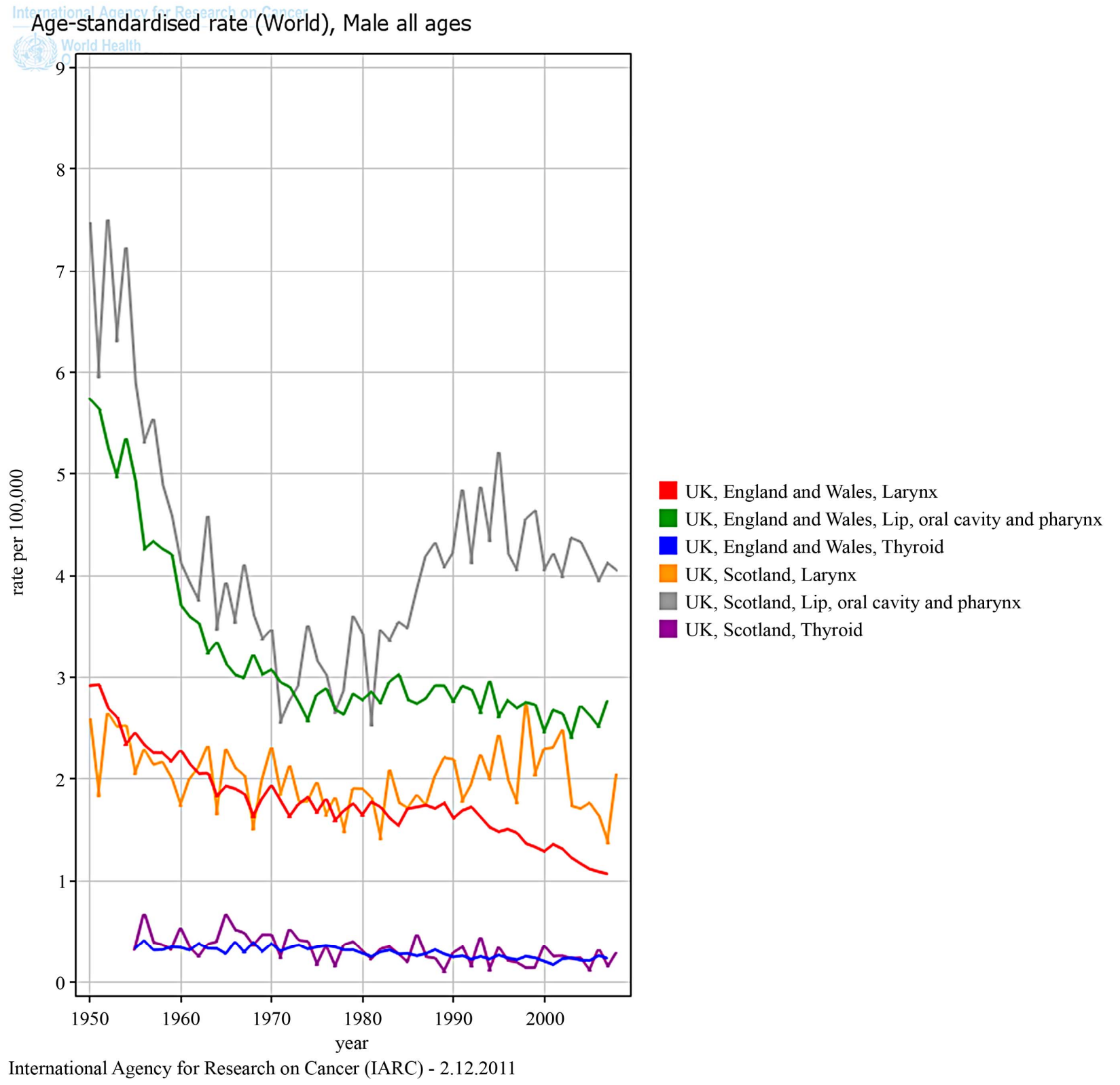

Figure 3. HNC mortality trends in males, UK.

when fallout radiation was greatest in England and Wales during nuclear weapon testing prior to the 1962 test ban treaty. Population-based data from the North of England in thyroid cancers in young people ( $<25$ yrs) between 1968-1997 found a significant increase following the Chernobyl nuclear accident [9]. In particular, the increase in incidence was much greater in Cumbria.

An increasing BMI has been positively association with thyroid cancer risk [10]. Scotland has one of the highest levels of obesity (prevalence $25.5 \%$ 2003) amongst European countries, second only to the Unites States [11]. Furthermore women in Scotland are more likely to be obese than women in England with similar levels of obesity amongst Scottish and English men [11].

\subsection{Laryngeal Cancer}

Laryngeal cancer is the fourteenth most common cancer among males in England and Wales accounting for 1.4\% of all cancers, whilst numbers of newly diagnosed cases and deaths in females are small [12]. Overall, age standardised incidence has fluctuated around 6 per 100,000 over the period 1971-1997, rising slightly in the late 1980s (congruent with smoking patterns) and subsequently declining. Smoking is the dominant risk factor for glottal cancers while alcohol is the major risk factor for cancers of the supra glottis. Over the last 30 years the use of tobacco in England has declined [13] which has been suggested as a possible contributory factor to the 


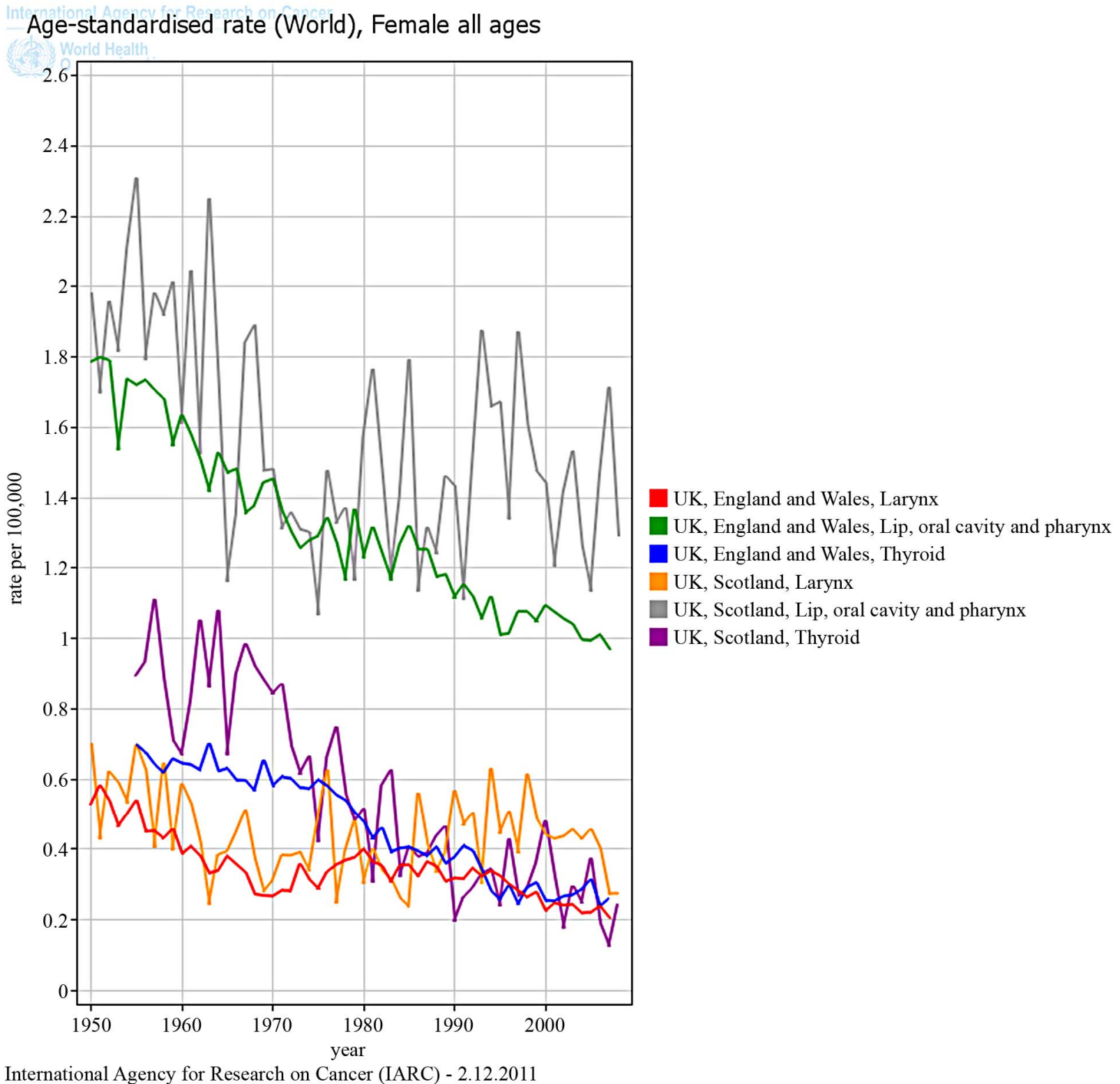

Figure 4. HNC Mortality trends in females, UK.

reduced incidence of head and neck cancers strongly associated with its use.

A recent study by Conway [14] on HNC risk factors used data from 15 case control studies enrolled on the International Head and Neck Cancer Epidemiology Consortium (INHANCE) with detailed information on cigarette smoking and alcohol consumption. Smoking risks were greater for cancers of the larynx than for the oral cavity or pharynx while alcohol risks were greater for cancers of the oral cavity and pharynx.

\subsection{Oral \& Pharyngeal Cancer}

Oral and pharyngeal cancer is the sixth most common cancer in the world [15].
The incidence of oral cancer among young people in the UK has been increasing since the 1970s and age has been suggested to be a strong independent predictor of survival [16].

Increasing incidence of oral carcinoma among young patients has also been reported in Europe and the USA [17]. There have been previous reports of increasing incidence at young adult ages and mortality from oral, pharyngeal and laryngeal cancers in Scotland in both sexes $[18,19]$.

Increasing alcohol consumption was associated with an increased risk of cancers of the oral cavity and pharynx in a study of over 1.2 million UK women [20]. Alcohol consumption is a recognised risk factor and this 
has been shown to be associated with an increase in oral cavity cancers [21]. It must be noted however that alcohol is not an initiator of carcinogenesis, it is a promoter (or co-carcinogen)-therefore not an independent risk factor for head and neck squamous cell carcinoma, except at the highest levels.

Strong epidemiologic and laboratory evidence document an association between tonsil cancer and human papilloma virus [22-37] particularly in younger patients without the usual risk factors of alcohol or smoking. A recent systematic review and meta-analysis on HPV and head and neck squamous cell carcinoma in specific sites showed the strongest and most consistent association was for tonsil cancer, and the magnitude of this association was consistent with an infectious aetiology [23].

Within the UK, there has been a 51\% increase in oral and oropharyngeal squamous cell carcinoma in men between 1989 and 2006, from 7 per 100,000 to 11 per 100,000 [38].

Oropharyngeal cancer has shown the greatest rate of increase of any cancer in Scotland. Although increased incidence was noted in all sub-sites, the greatest rise was noted for tonsil and base of tongue with a 2.9-fold increase in men compared to women [39]. Mortality from oral cancer has been on the decline in most Western European countries since the 1980s but there are persisting upward trends noted in Scotland alongside Belgium, Denmark, Greece and Portugal [40].

Different risk profiles have been identified with HPV positive HNSCC cancer versus HPV negative HNSCC [41], defining two distinct aetiological processes. HPV positive HNSCC has been associated with certain changes in patterns of sexual behaviour. One of the largest pooled analysis studies, noted an association of oropharyngeal cancer with a history of six or more lifetime partners, four or more lifetime oral sex partners and in men, an earlier age at first sexual intercourse [42]. A case-control study of 240 patients stratified by tumour HPV-16 status in HNSCC noted an independent association with increasing number of oral sex partners [36]. A recently published cross-sectional study $(n=5579)$ in the United States by Gillison et al. [43] found the prevalence of oral HPV was uncommon among sexually inexperienced individuals, was 8-fold higher amongst sexually experienced individuals and significantly increased with the number of sexual partners. Furthermore, oral HPV infection was approximately 3-fold higher in men than women, with the prevalence of HPV-16 more than 5-fold higher and a bimodal age pattern, with peak prevalence in individuals aged 30 - 34 years and 60 - 64 years was noted. The authors suggest that these findings may explain the rise of oropharyngeal cancer in younger individuals and in men.

In Great Britain, comparison between NATSAL I/II
(The National Survey of Sexual Attitudes and Lifestyles) surveys carried out in the 1990 and 2000 respectively, have shown changing sexual behaviours [44]. In particular, an earlier age of first intercourse (median age 16yrs), an increase in the average number of lifetime partners, concurrent partners and oral/anal intercourse was shown.

From two large prospective head and neck cancer cohorts, patients in Scotland presented at a younger age and significantly more patients in Scotland had advanced stage III/IV laryngeal cancer [45]. In the West of Scotland, 5 year disease specific survival from oral and oropharyngeal cancer has been reported as $50 \%$ and overall survival as $35 \%$ with pathological nodal stage and perineural invasion identified as prognostic factors [46].

When considered by level of social deprivation, survival from cancers of the oral cavity and pharynx in Scotland is lower among persons from the most deprived areas, and it is among such persons that the recent increases in occurrence of cancers of the oral cavity and pharynx have primarily occurred [47].

\subsection{Study Limitations}

The study contained a large number of participants and includes three decades of data. This invariably could introduce bias given the size and the changes over time in collecting and analysing data. Further analysis is not possible as only aggregate data is available. There have also been changes in risk factor behaviour by region in the time interval and a number of improvements in HNC care including earlier diagnosis, improved referral pathways, better diagnostics and scans as well as better, less toxic treatments that have improved survival. This study takes that into consideration and only aims to provide time trends with an insight into the broad epidemiologic changes by HNC sub-site.

\section{CONCLUSION}

In the UK, Scotland had higher incidence rates for cancers of the larynx, thyroid, oral cavity and pharynx compared with England. Mortality has reduced in England from all the HNC sub-sites but has increased in Scotland for laryngeal, oral \& pharyngeal cancers. Although socioeconomic deprivation and its relation to higher alcohol and tobacco consumption have been highlighted as drivers, further studies are required. The findings of this study will facilitate understanding of these regional differences in HNC epidemiology in the UK with a view to better identification of at-risk groups, and ensuring targeted cancer prevention and control measures.

\section{ACKNOWLEDGEMENTS}

The International Agency for Research on Cancer (IARC) for the cancer incidence trends using the cancer incidence in 5 continents database 
and mortality data from the World Health Organization, mortality database.

\section{REFERENCES}

[1] Wartofsky, L. (2010) Increasing world incidence of thyroid cancer: Increased detection or higher radiation exposure? Hormones, 9, 103-108.

[2] Olaleye, O., Ekrikpo, U., Moorthy, R., Lyne, O., Wiseberg, J., Black, M. and Mitchell, D. (2011) Increasing incidence of differentiated thyroid cancer in South East England: 1987-2006. European Archives of Oto-RhinoLaryngology, 268, 899-906. doi:10.1007/s00405-010-1416-7

[3] Reynolds, R.M., et al. (2005) Changing trends in incidence and mortality of thyroid cancer in Scotland. Clinical Endocrinology, 62, 156-162. doi:10.1111/j.1365-2265.2004.02187.x

[4] Wier, J., Brewster, D.H. and Strachan, M.W.J. (2003) The epidemiology of thyroid cancer in Scotland, 19601999. Endocrine Abstracts, 5, 261.

[5] Davies, L. and Welch, H.G. (2006) Increasing incidence of thyroid cancer in the United States, 1973-2002. JAMA, 295, 2164-2167. doi:10.1001/jama.295.18.2164

[6] Morris, L. and Myssiorek, D. (2010) Improved detection does not fully explain the rising incidence of well-differentiated thyroid cancer: A population-based analysis. The American Journal of Surgery, 200, 454-461. doi:10.1016/j.amjsurg.2009.11.008

[7] Cramer, J.D., et al. (2010) Analysis of the rising incidence of thyroid cancer using the surveillance epidemicology and end results national cancer data registry. Surgery, 148, 1147-1153. doi:10.1016/j.surg.2010.10.016

[8] dos Santos Silva, I. and Swedlow, A.J. (1993) Thyroid cancer epidemiology in England and Wales: Time trends and geographical distribution. British Journal of Cancer, 67, 330-340. doi:10.1038/bjc.1993.61

[9] Cotterill, S.J., Pearce, M.S. and Parker, L. (2001) Thyroid cancer in children and young adults in the north of England. Is increasing incidence related to the Chernobyl accident? European Journal of Cancer, 37, 1020-1026. doi:10.1016/S0959-8049(00)00449-4

[10] Kitahara, C.M., Platz, E.A., Freeman, L.E., Hsing, A.W., Linet, M.S., Park, Y., Schairer, C., Schatzkin, A., Shikany, J.M. and Berrington de González, A. (2011) Obesity and thyroid cancer risk among US men and women: A pooled analysis of five prospective studies. Cancer Epidemiology, Biomarkers \& Prevention, 20, 464-472.

[11] Grant, I., Fischbacher, C. and Whyte, B. (2007) Obesity in Scotland: An epidemiology briefing. ScotPHO, ISD, Edinburgh.

[12] Office of National Statistics (2006) Cancer statistics registrations. Registrations of cancer diagnosed in 2004, England. Series MB1 No. 35.

[13] Goddard, E. (Ed.) (2006) Smoking and drinking amongst adults, 2005. Office of National Statistics.

[14] Conway, D.I. (2010) Everything in Moderation? Evi-
dence-Based Dentistry, 11, 89-90. doi:10.1038/sj.ebd.6400744

[15] Warnakulasuriya, S. (2009) Global epidemiology of oral and oropharyngeal cancer. Oral Oncology, 45, 309-316. doi:10.1016/j.oraloncology.2008.06.002

[16] Warnakulasuriya, S., Mak, V. and Moller, H. (2003) Oral cancer survival in young people in South East England. Oral Oncology, 43, 982-986.

[17] Shiboski, C.H., Schmidt, B.L. and Jordan, R.C. (2005) Tongue and tonsil carcinoma: Increasing trends in the US population ages 20 - 44 years. Cancer, 103, 1843-1849.

[18] Swerdlow, A.J., dos Santos Silva, I., Reid, A., Qiao, Z., Brewster, D.H. and Arrundale, J. (1998) Trends in cancer incidence and mortality in Scotland: Description and possible explanations. British Journal of Cancer, 77, 1-54. doi:10.1038/bjc.1998.424

[19] MacFarlane, G.J., Evstifeeva, T.V., Scully, C. and Boyle, P. (1993) The descriptive epidemiology of pharyngeal cancer in Scotland. European Journal of Epidemiology, 9, 587-590. doi:10.1007/BF00211431

[20] Allen, N.E., Beral, V., Casabonne, D., Kan, S.W., Reeves, G.K., Brown, A. and Green, J. on Behalf of Million Women Study Collaborators (2009) Moderate alcohol intake and cancer incidence in women. Journal of the National Cancer Institute, 101, 296-305.

[21] Hindle, I., Downer, M.C., Moles, D.R. and Speight, P.M. (2000) Is alcohol responsible for more intra-oral cavity cancer? Oral Oncology, 36, 328-333. doi:10.1016/S1368-8375(00)00020-8

[22] Klaussman, J.P., Weissenborn, S.J., Wieland, U., et al. (2003) Human papillomavirus-positive tonsillar carcinomas: A different tumour entity? Medical Microbiology and Immunology (Berlin), 192, 129-132. doi:10.1007/s00430-002-0126-1

[23] Hobbs, C.G., Sterne, J.A., Bailey, M., Heyderman, R.S., Birchall, M.A. and Thomas, S.J. (2006) Human papillomavirus and head and neck cancer: A systematic review and meta-analysis. Clinical Otolaryngology, 31, 259-266.

[24] Riechelmann, H. (2010) Human papilloma virus in head and neck cancer. Laryngo-Rhino-Otologie, 89, 43-48.

[25] Gillespie, M.B., Smith, J., Gibbs, K., McRackan, T., Rubinchik, S., Day, T.A. and Sutkowski, N. (2008) Human papilloma virus and head and neck cancer: A growing concern. Journal-South Carolina Medical Association, 104, 247-251.

[26] Badaracco, G. and Venuti, A. (2007) Human papilloma virus therapeutic vaccines in head and neck tumors. Expert Review of Anticancer Therapy, 7, 753-766.

[27] Lopez-Lizarraga, E., Sanchez-Corona, J., Montoya-Fuentes, H., Bravo-Cuellar, A., Campollo-Rivas, O., LopezDemerutis, E., Morgan-Villela, G., Arcaute-Velazquez, F., Monreal-Martinez, J.A. and Troyo, R. (2000) Human papilloma virus in tonsillar and nasopharyngeal carcinoma: Isolation of HPV subtype 31. Ear, Nose \& Throat Journal, 79, 942-944.

[28] Luginbuhl, A., Sanders, M. and Spiro, J.D. (2009) Prevalence, morphology, and prognosis of human papilloma virus in tonsillar cancer. Annals of Otology, Rhinology \& 
Laryngology, 118, 742-749.

[29] Pintos, J., Black, M.J., Sadeghi, N., Ghadirian, P., Zeitouni, A.G., Viscidi, R.P., Herrero, R., Coutlee, F. and Franco, E.L. (2008) Human papillomavirus infection and oral cancer: A case-control study in Montreal, Canada. Oral Oncology, 44, 242-250.

[30] Tran, N., Rose, B.R. and O’Brien, C.J. (2007) Role of human papillomavirus in the etiology of head and neck cancer. Head \& Neck, 29, 64-70.

[31] Begum, S., Cao, D., Gillison, M., Zahurak, M. and Westra, W.H. (2005) Tissue distribution of human papillomavirus 16 DNA integration in patients with tonsillar carcinoma. Clinical Cancer Research, 11, 5694-5699.

[32] Gillison, M.L. and Lowy, D.R. (2004) A causal role for human papillomavirus in head and neck cancer. Lancet, 363, 1488-1489. doi:10.1016/S0140-6736(04)16194-1

[33] Ryerson, A.B., Peters, E.S., Coughlin, S.S., Chen, V.W., Gillison, M.L., Reichman, M.E., Wu, X., Chaturvedi, A.K. and Kawaoka, K. (2008) Burden of potentially human papilloma-virus associated cancers of the oropharynx and oral cavity in the US, 1998-2003. Cancer, 113, 2901-2909.

[34] Mehanna, H., et al. (2010) Oropharyngeal carcinoma related to human papillomavirus. Institute of Head and Neck Studies and Education, University Hospital, Coventry.

[35] Wiest, T., Schwarz, E., Enders, C., et al. (2002) Involvement of intact HPV 16 E6/E7 gene expression in head and neck cancers with unaltered p53 status and perturbed pRb cell cycle control. Oncogene, 21, 1510-1517. doi:10.1038/sj.onc.1205214

[36] Van Houten, V.M., Snijders, P.J., van den Brekel, M.W., et al. (2001) Biological evidence that human papillomaviruses are etiologically involved in a subgroup of head and neck squamous cell carcinomas. International Journal of Cancer, 93, 232-235. doi:10.1002/ijc.1313

[37] Koskinen, W.J., Chen, R.W., Leivo, I., et al. (2003) Prevalence and physical status of human papillomavirus in squamous cell carcinomas of the head and neck. International Journal of Cancer, 107, 401-406. doi:10.1002/ijc.11381

[38] Mehanna, H., Jones, T.M., Gregoire, V. and Ang, K.K. (2010) Oropharyngeal carcinoma related to human paillomavirus. British Medical Journal, 340, c1439.

\section{doi:10.1136/bmj.c1439}

[39] Junor, E.J., Kerr, G.R. and Brewster, D.H. (2010) Oropharyngeal cancer: Fastest increasing cancer in Scotland, especially in men. British Medical Journal, 340, c2512. doi:10.1136/bmj.c2512

[40] La Vecchia, C., Lucchini, F., Negri, E. and Levi, F. (2004) Trends in oral cancer mortality in Europe. Oral Oncology, 40, 433-439. doi:10.1016/j.oraloncology.2003.09.013

[41] Gillison, M.L., D’Souza, G., Wesra, W., et al. (2008) Distinct risk factor profiles for human papillomavirus type 16-positive and human papillomavirus type 16-negative head and neck cancers. Journal of the National Cancer Institute, 100, 1-14. doi:10.1093/jnci/djn025

[42] Heck, J.E., Bethiller, J., Vaccarella, S., et al. (2010) Sexual behaviours and the risk of head and neck cancers: A pooled analysis in the International Head and Neck Cancer Epidemiology (INHANCE) consortium. International Journal of Epidemiology, 39, 166-181. doi:10.1093/ije/dyp350

[43] Gillison, M.L., Broutian, T., Pickard, R.K.L., et al. (2012) Prevalence of oral HPV infection in the United States, 2009-2010. JAMA, Published Online.

[44] Copas, A.J., Wellings, K., Erens, B., et al. (2002) The accuracy of reported sensitive sexual behaviour in Britain: Exploring the extent of change 1990-2000. Sexually Transmitted Infections, 78, 26-30. doi:10.1136/sti.78.1.26

[45] MacKenzie, K., Savage, S.A. and Birchall, M.A. (2009) Processes and outcomes of head and neck cancer patients from geographically disparate regions of the UK. A comparison of Scottish and English cohorts. European Journal of Surgical Oncology, 35, 1113-1118. doi:10.1016/j.ejso.2009.04.001

[46] McMahon, J.D., Robertson, G.A., Liew, C., McManners, J., Mackenzie, F.R., Hislop, W.S., Morley, S.E., Devine, J., Carton, A.T., Harvey, S., Hunter, K. and Robertson, A.G. (2011) Oral and oropharyngeal cancer in the West of Scotland-long-term outcome data of a prospective audit 1999-2001. British Journal of Oral and Maxillofacial Surgery, 49, 92-98. doi:10.1016/j.bjoms.2009.12.013

[47] Macfarlane, G.J., Sharp, L., Porter, S. and Franceschi, S. (1996) Trends in survival from cancers of the oral cavity and pharynx in Scotland: A clue as to why the disease is becoming more common? British Journal of Cancer, 73, 805-808. doi:10.1038/bjc.1996.141 